\title{
Utility of PET-CT versus CT in staging colorectal cancer
}

\author{
Daniela Z. Hernández-Oliver ${ }^{* *}$ and José A. Serna-Macías² \\ ${ }^{1}$ PET-CT Department; ${ }^{2}$ Department of Nuclear Medicine. Hospital Ángeles Pedregal, Mexico City, Mexico
}

\begin{abstract}
Introduction: Colorectal cancer ranks third in incidence in Mexico and the world. The stage is one of the main prognostic factors. Due to the high percentage of cases with metastatic disease at diagnosis in Mexico, the correct choice of imaging studies is essential. Objective: Determine the usefulness of PET-CT with ${ }^{18}$ F-FDG vs. CT, in staging. Methods: Retrospective study. Patients with CRC and PET-CT and CT for staging, in a private hospital in Mexico were included. Demographic data, primary tumor site, histology, were collected, and primary and secondary lesions and their characteristics were recorded by PET-CT and CT. Results: 15 patients were included. $60 \%$ were men, the median age was 64 years. $73.3 \%$ developed in the left colon and $100 \%$ were adenocarcinoma. The PET-CT identified $73.3 \%$ of the primary lesions and $66.7 \%$ of the regional lymph nodes. Also, 9 cases with metastatic disease. Thus, the $N$ and $M$ staging of 8 and 4 patients, respectively, changed. The SUVmax of the primary lesions was 8.39; finding a significant correlation with the laterality of the primary tumor. Conclusion: PET-CT proved to be more efficient in detecting primary and secondary lesions versus CT.
\end{abstract}

Key words: Colorectal cancer. PET-CT. Positron emission tomography. Computed tomography. Staging. ${ }^{18}$ F-FDG.

\section{Utilidad de la PET-CT frente a la TC en la estadificación del cáncer colorrectal}

\section{Resumen}

Introducción: El cáncer colorrectal ocupa el tercer lugar en incidencia en México y el mundo. El estadio es de los principales factores pronósticos. Debido al alto porcentaje de casos con enfermedad metastásica al diagnóstico en México, la correcta elección de estudios de imagen es fundamental. Objetivo: Determinar la utilidad de la tomografía por emisión de positrones/tomografía computarizada (PET-CT) con 18-fluoro-2-desoxi-d-glucosa $\left({ }^{18} \mathrm{~F}-\mathrm{FDG}\right)$ vs. la tomografía computarizada (TC) en la estadificación. Métodos: Estudio retrospectivo. Se incluyeron pacientes con cáncer colorrectal y PET-CT y TC de estadificación, en un hospital privado de México. Se recolectaron datos demográficos, sitio de tumor primario e histología, y se registraron las lesiones primarias, secundarias y sus características por PET-CT y TC. Resultados: Se incluyeron 15 pacientes. El $60 \%$ fueron hombres, la mediana de edad fue de 64 años. El $73.3 \%$ se desarrollaron en colon izquierdo y el 100\% fueron adenocarcinoma. La PET-CT identificó el $73.3 \%$ de las lesiones primarias y el $66.7 \%$ de los ganglios linfáticos regionales; también nueve casos con enfermedad metastásica. Así, cambió la estadificación N y M de ocho y cuatro pacientes respectivamente. El valor estandarizado de captación máximo de las lesiones primarias fue de 8.39, encontrando correlación significativa con la lateralidad del tumor primario. Conclusión: La PET-CT demostró ser más eficiente en la detección de las lesiones primarias y secundarias que la TC.

Palabras clave: Cáncer colorrectal. PET-CT. Tomografía por emisión de positrones. Tomografía computarizada. Estadificación. ${ }^{18}$ F-FDG.

\section{Correspondence:}

*Daniela Z. Hernández-Oliver

E-mail: aleinad_amyeluz@ @otmail.com

1665-9201/C 2021 Sociedad Mexicana de Oncología. Published by Permanyer. This is an open access article under the terms of the CC BY-NC-ND license (http://creativecommons.org/licenses/by-nc-nd/4.0/).
Date of reception: 18-02-2021

Date of acceptance: $28-07-2021$

DOI: 10.24875/j.gamo.M21000216
Available online: 16-11-2021 Gac Mex Oncol. 2021;20(4):40-44

www.gamo-smeo.com 


\section{Introduction}

Colorectal cancer (CRC) is the most common digestive neoplasm. In Mexico, until 2018, it ranked third in incidence for both genders, with a total of 14,900 new cases ( $7.8 \%$ of all new cancer cases); in men, it ranked second in incidence, with 7,795 cases, and in women fifth, with 7,105 cases. As for mortality, 5,700 deaths were recorded for colon cancer $(6.8 \%$ of all cancer deaths), while 1,325 deaths were recorded for rectal cancer $(1.6 \% \text { of total cancer deaths })^{1}$.

Approximately $90 \%$ of colorectal malignancies are adenocarcinomas, among which the most common is the intestinal variant ${ }^{2}$.

It is a multifactorial disease process, with an etiology that involves genetic factors, environmental exposure, and inflammatory conditions of the digestive tract. Positive family history is found in approximately $10-20 \%$ of all CRC patients, with variable risk according to the number and degree of affected relatives and age at diagnosis. On the other hand, there is a subgroup of approximately $5-7 \%$ of patients with CRC that is affected by a well-defined hereditary CRC syndrome ${ }^{3}$.

Age is a well-known risk factor for CRC. The timeline for the progression of early premalignant lesions to cancer ranges from 10 to 20 years, with a median age at diagnosis of 68 years in men and 72 years in women ${ }^{4}$.

Given that early stage colon cancer is typically asymptomatic, screening plays an important role in curable cancerous lesions detection, as well as in precancerous lesions (adenomatous colon polyps) detection, which has had a major impact on the decrease in the incidence of $\mathrm{CRC}$ and mortality rates in recent decades.

However, the adoption of new practices in diagnosis and treatment has also allowed to reduce mortality by $50 \%$ in the most developed countries. In particular, the various diagnostic imaging modalities enable to improve therapeutic decision-making, new therapies response and efficacy evaluation, and relapse early detection $^{5}$. CRC stage at the time of diagnosis is one of the main prognostic factors; 5 -year survival is $91 \%$ when it is detected at a localized stage, $71 \%$ when regional involvement is detected, and $17 \%$ when there is distant disease.

In the Hispanic population, $38 \%$ of patients are diagnosed with localized disease, $36 \%$ with regional disease, and $21 \%$ with distant metastatic disease ${ }^{2}$.

In this context, and given the high percentage of patients with metastatic disease at diagnosis and the impact this has on survival, the choice of imaging techniques plays a fundamental role in early diagnosis and correct staging. Contrast tomography of the abdomen and pelvis offers a sensitivity of $90 \%$ for the detection of T3-T4 tumors, with a specificity of $69 \%$, while for lymph node staging, sensitivity is $71 \%$, with a specificity of $67 \%$. Recent works have demonstrated the accuracy of positron-emission tomography-computed tomography (PET-CT) for initial staging, by clarifying equivocal findings on conventional imaging and evaluating metastatic disease.

\section{Material and methods}

Our study included 15 patients with CRC confirmed diagnosis who underwent staging PET-CT and computed tomography (CT), with a difference between studies of less than three weeks, at Hospital Ángeles Pedregal. Patient characteristics were collected from the medical record, including gender, age at diagnosis, primary tumor site and histological type, and date of PET-CT and CT performance for staging.

These cases were also evaluated using the dedicated PET-CT workstation and Carestream Health ${ }^{\odot}$ : primary lesion (identified or not, size and maximum standardized uptake value [SUVmax]) and secondary lesions (identified or not, location, number, size and SUVmax).

Statistical analysis was carried out using IBM SPSS program, version 25. Qualitative variables were described using frequencies and percentages, while central tendency measures were used for quantitative variables. The results were expressed using tables or graphs.

\section{Results}

Between 2016 and 2020, 30 PET-CT and CT scans were performed for the staging of 15 patients with a CRC confirmed diagnosis at Hospital Ángeles Pedregal, out of which $40 \%$ were women and $60 \%$ men (Table 1). Regarding the age of this population, a range between 41 and 88 years was found, with a mean of $64 \pm 12.6$ years (Fig. 1).

When frequency was evaluated by primary tumor site in CRC-diagnosed patients, $40 \%$ of cancers were found to have developed in the left colon, $26.7 \%$ in the right colon, and $33.3 \%$ in the rectum (Fig. 2). As for histology, $100 \%$ of included patients had epithelial tumors of the adenocarcinoma type.

On patient-based analysis, PET-CT identified 11 of the 15 primary lesions, i.e., $73.3 \%$ (Table 2), while contrast-enhanced CT detected 53.3\% (8/15). 
Table 1. Distribution by gender of colorectal cancer patients who had positron-emission tomography/computed tomography and computed tomography scans available

\begin{tabular}{|l|c|c|c|c|}
\hline & Frequency & Percentage & Valid percentage & Cumulative percentage \\
\hline Females & 6 & 40.0 & 40.0 & 40.0 \\
\hline Males & 9 & 60.0 & 60.0 & 100.0 \\
\hline Total & 15 & 100.0 & 100.0 & \\
\hline
\end{tabular}

Table 2. Frequency and percentage of primary lesions detection by positron-emission tomography/computed tomography in patients with colorectal cancer

\begin{tabular}{|l|c|c|c|c|}
\hline & Frequency & Percentage & Valid percentage & Cumulative percentage \\
\hline No & 4 & 26.7 & 26.7 & 26.7 \\
\hline Yes & 11 & 73.3 & 73.3 & 100.0 \\
\hline Total & 15 & 100.0 & 100.0 & \\
\hline
\end{tabular}

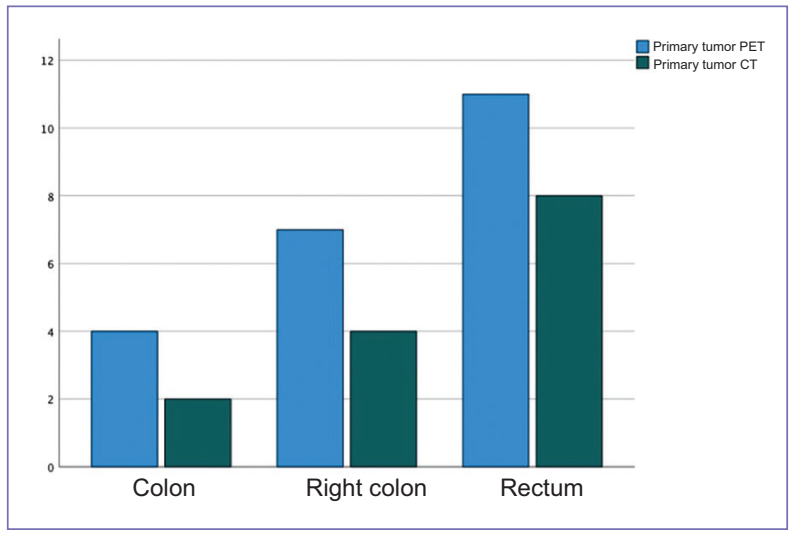

Figure 1. Frequency of primary tumor detection by PET and CT, according to the site of development (colon, right colon and rectum).

PET: positron-emission tomography; CT: computed tomography.

In addition, based on primary lesion site, PET-CT identified the primary lesion in $60 \%$ of left colon cases $(4 / 6)$, in $66 \%$ of right colon cases (3/4) and in $80 \%$ of rectum cases $(4 / 5)$, while CT identified the primary lesion in $33 \%$ of left colon cases $(2 / 6)$, in $50 \%$ of right colon cases $(2 / 4)$ and in $80 \%$ of rectal cases $(4 / 5)$ (Fig. 3).

Patient-based analysis was also carried out for locoregional lymph nodes, distant lymph nodes, metastases to the lung, liver, central nervous system (CNS) and other sites (including ovaries, bone, and

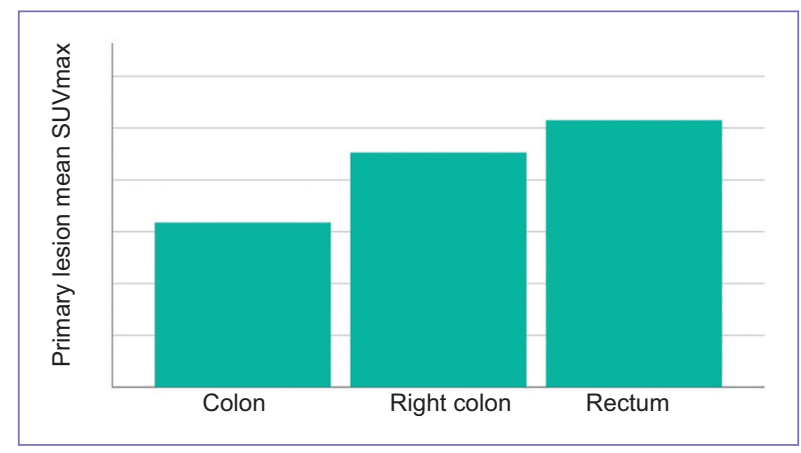

Figure 2. Primary lesion SUVmax by site of development (colon, right colon and rectum).

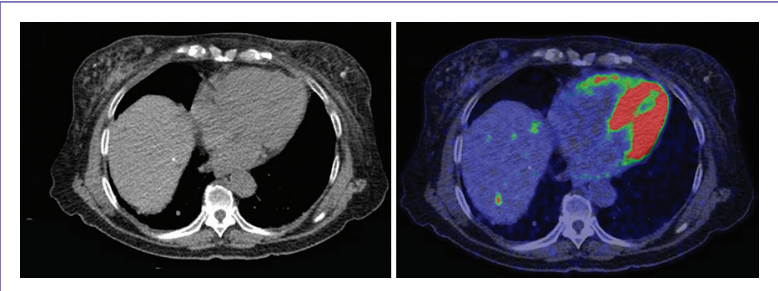

Figure 3. Hypermetabolic liver metastases in a patient with a history of rectosigmoid junction adenocarcinoma, not visualized by computed tomography.

subcutaneous cellular tissue implants). PET-CT identified locoregional lymph nodes in $66.7 \%$ of cases vs. $33.3 \%$ that could be identified by CT (10 vs. 5); 
Table 3. Lesions' SUVmax average frequencies per patient

\begin{tabular}{|l|c|}
\hline N & 15 \\
\hline Mean & 7.8507 \\
\hline Median & 6.7300 \\
\hline Deviation & 2.81761 \\
\hline Range & 10.02 \\
\hline Minimum & 4.34 \\
\hline Maximum & 14.36 \\
\hline
\end{tabular}

PET-CT was also superior for the detection of distant lymph nodes (3 vs. 1) and liver metastases (3 vs. 2); in addition, it identified one bone lesion that was not detected by CT.

Both showed comparable results for lung metastases, and in no patient were CNS metastases detected. In total, PET-CT was able to detect a total of 30 lesions, in comparison with $\mathrm{CT}$, which detected a total of 18 lesions, both including the primary lesion.

The semi-quantitative analysis included SUVmax calculation, by means of regions of interest around the sites associated with 18-fluoro-2-deoxy-d-glucose ( $\left.{ }^{18} \mathrm{~F}-\mathrm{FDG}\right)$ abnormal uptake. If there was more than one lesion in an organ or system, the largest lesion was considered for analysis. Given that tumor infiltration sites per patient were not comparable, lesions' average SUVmax per patient was calculated, and a range between 4.34 and 14.36 was found, with a mean of $7.85 \pm 2.81$ (Table 3). The SUVmax values of the 11 primary lesions that were identified were also independently evaluated, with a range between 4.53 and 25.82 being found, with the lowest value being for a tumor in the left colon and the highest value for a tumor in the right colon. In the analysis by primary tumor site, the highest mean SUVmax that was obtained was 12.8 for tumors of the rectum (Fig. 4).

PET-CT and CT-obtained $\mathrm{N}$ and $\mathrm{M}$ staging was also evaluated, in which, by both methods, only one N1A patient was identified; PET-CT identified five N1B patients and three N2A patients, while CT identified four and two patients respectively; no lymph node involvement was identified in six patients by PET-CT and in eight patients by CT (Fig. 5).

In the evaluation of distant metastases (M), PET-CT identified three M1A, two M1B, and one M1C patient,

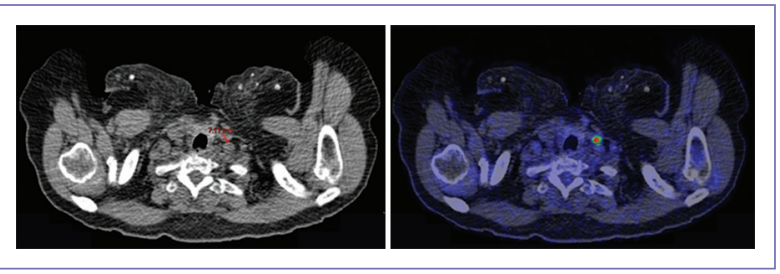

Figure 4. Hypermetabolic cervical lymph node metastasis in a patient with a history of adenocarcinoma of the rectum, not visualized by computed tomography.

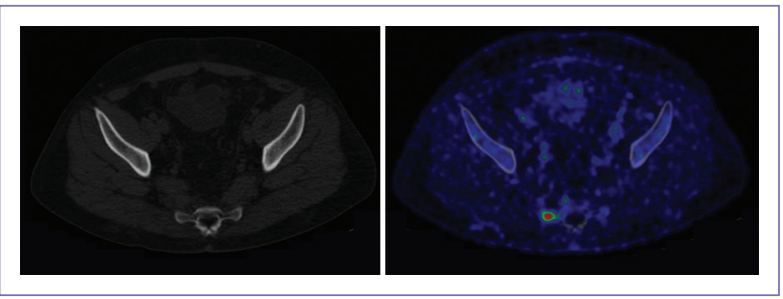

Figure 5. Hypermetabolic right sacrum metastasis in a patient with a history of right colon adenocarcinoma, not visualized by computed tomography.

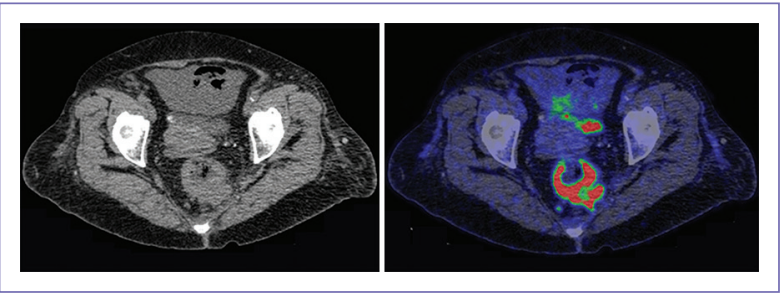

Figure 6. Hypermetabolic areas related to tumor activity, located on the rectosigmoid junction wall, as well as on sigmoid colon, with the latter not being visualized on computed tomography.

while CT identified two M1A patients and the same number of patients for M1B and M1C staging. No distant metastases were identified in nine patients by PETCT and in 10 patients by CT (Fig. 6).

\section{Discussion}

As reported in world statistics, CRC global incidence rate reported in women is 16.2 per 100,000 population, while for men it is 23.4 per 100,000 population, which indicates that the population served by Hospital Angeles Pedregal between 2016 and 2020 corresponds to the description of incidence by gender in the world ${ }^{1}$. 
The age group that is usually most affected by CRC has been described to be the group aged $\geq 65$ years for both genders, which is consistent with the four years retrospectively observed in our hospital, where median age was 70 years for men and 67 years for women. CRC laterality global prevalence is $70 \%$ for the left colon and $30 \%$ for right colon, which corresponds to the results of the four years evaluated in this study, where $73.3 \%$ was documented for the left colon (including the rectum) and $26.7 \%$ for the right colon ${ }^{3}$. As the literature shows, CRC adequate staging plays a key role for determining subsequent therapeutic management, which has a direct impact on patient survival and mortality ${ }^{3}$.

Regarding the main purpose of this study, PET-CT was shown to be superior to $\mathrm{CT}$ in primary tumor identification (73.3 vs. $53.3 \%$ ). In addition, it also demonstrated a higher capacity for detecting locoregional lymph nodes, distant lymph nodes, and liver metastases, and identified a bone lesion that was not detected by $\mathrm{CT}$.

However, for lung lesions, detection capacity for both methods was the same. Lymph node staging changed in eight patients, out of whom five cases had their staging increased and three had it decreased. In addition, in the evaluation of distant metastases, in four patients was the stage increased.

These changes in CRC patients initial staging could potentially modify the treatment strategy by up to $35 \%{ }^{5}$.

Although this study did not find a significant correlation between SUVmax and patient staging, verifying a relationship between SUVmax and primary tumor laterality was possible, where right colon tumors, which are associated with molecular characteristics of poorer prognosis, had higher SUVmax values.

\section{Funding}

This research has not received any specific grant from agencies of the public, commercial or non-profit sectors.

\section{Conflicts of interest}

The authors declare that they have no conflicts of interest.

\section{Ethical disclosures}

Protection of human and animal subjects. The authors declare that no experiments were performed on humans or animals for this research.

Confidentiality of data. The authors declare that they have followed the protocols of their work center on the publication of patient data.

Right to privacy and informed consent. The authors have obtained informed consent from the patients and/or subjects referred to in the article.

\section{References}

1. Bray F, Ferlay J, Soerjomataram I, Siegel RL, Torre LA, Jemal A. Global cancer statistics 2018: GLOBOCAN estimates of incidence and mortality worldwide for 36 cancers in 185 countries. CA Cancer J Clin. 2018;68(6): 394-424.

2. Torrecillas-Torres L, Cervantes-Sánchez G, Adame-González I, Bornstein-Quevedo L. Recomendaciones para diagnóstico y tratamiento de cáncer de colon y recto en México. Gac Mex Oncol. 2019;18(4):265-330.

3. Dekker E, Tanis PJ, Vleugels JLA, Kasi PM, Wallace MB. Colorectal cancer. Lancet. 2019;394(10207):1467-80.

4. Dragovich T. Colon Cancer: Practice essentials, background, pathophysiology [Internet]. Medscape; April 29, 2021. Available at: https://emedicine.medscape.com/article/277496-overview

5. Rodríguez-Fraile M, Cozar-Santiago MP, Sabate-Llobera A, Caresia-Arozteguid P, Delgado Boltone RC, Orcajo-Rinconf J, et al. FDG PET/ TC en el cáncer colorrectal. Rev Esp Med Nucl. 2020;39(1):57-66.

6. Nerad E, Lahaye MJ, Maas M, Nelemans P, Bakers FCH, Beets GL, et al. Diagnostic accuracy of CT for local staging of colon cancer: A systematic review and meta-analysis. Am J Roentgenol. 2016;207(5): 984-95. 